\title{
Assessment of Atmospheric Environmental Quality in Baoji City
}

\author{
Yin-ge LIU* \\ Key Laboratory of Disaster Monitoring and Mechanism \\ Simulating in Shaanxi Province \\ Department of Geography and Environmental \\ Engineering, \\ Baoji College of Arts and Science, \\ Baoji 721013, China \\ e-mail: yingeliu@163.com \\ Yong-gang ZHANG \\ Key Laboratory of Disaster Monitoring and Mechanism \\ Simulating in Shaanxi Province \\ Department of Geography and Environmental \\ Engineering, \\ Baoji College of Arts and Science, \\ Baoji 721013, China
}

\author{
Peng-ying SHI \\ Key Laboratory of Disaster Monitoring and Mechanism \\ Simulating in Shaanxi Province \\ Department of Geography and Environmental \\ Engineering, \\ Baoji College of Arts and Science, \\ Baoji 721013, China
}

regions, but also can help to guide the environmental quality management.

\section{DATA AND METHODS}

\section{A. Data}

Air samplings were collected from four monitoring stations in different areas from 2007 to 2013 and the climate elements including temperature, humidity, wind speed and precipitation were obtained from weather station of Baoji. The four monitoring stations were selected based on characteristics of spatial pattern of Baoji and current pollution situation. The monitored stations scattered in Zhuyuangou, school district, city center and town hospital. The three parameters, including $\mathrm{SO}_{2}, \mathrm{NO}_{2}$ and PM10 were use in atmospheric quality evaluation indexes.

\section{B. Assessment Methods}

According to the actual situation, comprehensive index and the Daniel trend test of spearman rank correlation coefficient method are used in air quality evaluation [89].Comprehensive air pollution index can reflect degree of air contaminated and pollutant load coefficients are used to evaluate trend of air pollutants. The evaluation method is as follows.

Various pollutants is calculated as Eq.(1).

$$
p_{i}=\frac{a_{i}}{b_{i}}
$$

The comprehensive pollution index is calculated as Eq.(2). 


$$
P=\sum_{i=1}^{n} p_{i}
$$

Pollution load is calculated as Eq.(3).

$$
c_{i}=\frac{p_{i}}{P}
$$

Among them, the $a_{i}$ is the $i^{\text {th }}$ average of the air pollutant concentration, $b_{i}$ is the $i^{\text {th }}$ value of environmental quality standard of air pollutant and $P_{i}$ is $i^{\text {th }}$ index of air pollutants. $P$ is environmental air pollution index and $c_{i}$ is the $i^{\text {th }}$ environment pollution load coefficient.

Daniel trend test of spearman rank correlation coefficient is a commonly method used to analyze the tendency of air environmental pollution [6]. The rank correlation coefficient can be used in a small sample and the single factor correlation test, moreover the method is simple and high accuracy. Equation is as follows.

$$
\begin{aligned}
& R_{S}=1-\frac{6 \sum_{i=i}^{n} d_{i}^{2}}{Y^{3}-Y} \\
& d_{i}=x_{i}-y_{i}
\end{aligned}
$$

The Among them, $\mathrm{Y}$ is the total cycle time size. The Rs is rank correlation coefficient. $x_{i}$ is the ordinal number of air pollutants. $y_{i}$ is ordinal number. When $R_{s}>0$, it show concentration of air pollutants is increased, and when $R_{s}<0$, (2) concentration of air pollutants is decreasing trend. The absolute value indicates the strength changes of concentration of air pollutants [8-11]. When / Rs $/ \geq W p$ (Significant level test), it shows that the trend of air pollution is significant change. Otherwise, it is no significant change. According to the national environmental air quality standard [10-11] and actual conditions of Baoji city, Atmospheric

\begin{tabular}{|c|c|c|c|}
\hline \multirow{2}{*}{ Pollutants } & \multicolumn{3}{|c|}{$\begin{array}{l}\text { Class } \\
\text { standard }\end{array}$} \\
\hline & 1 & 2 & . \\
\hline $\mathrm{SO}_{2}$ & 0.02 & 0.06 & 0.10 \\
\hline $\mathrm{NO}_{2}$ & 0.04 & 0.08 & 0.12 \\
\hline PM10 & 0.04 & 0.10 & 0.15 \\
\hline
\end{tabular}
environmental quality is divided into three standards and the three levels are listed as the following: not pollution, smaller pollution, and high risk (Tab. 1).

\section{RESULTS ANALYSIS}

\section{A. Atmospheric Quality Assessment}

The climate elements in Baoji are shown in (Tab.2). It can be seen that the highest temperature is in summer, and the lowest temperature is in water. The largest average precipitation and humidity are in autumn. The biggest wind speed is in spring and least wind speed is in autumn. Except

\begin{tabular}{|c|c|c|c|c|c|c|}
\hline Climate elements & Spring & Summer & Autumn & Winter & $\begin{array}{l}\text { Annual } \\
\text { average }\end{array}$ & $\begin{array}{c}\text { Trend } \\
\text { rater/year }\end{array}$ \\
\hline $\begin{array}{l}\text { Maximum } \\
\text { temperature } \\
\left({ }^{\circ} \mathrm{C}\right)\end{array}$ & 14.0 & 29.0 & 26.0 & 8.0 & 19.0 & 0.01 \\
\hline $\begin{array}{l}\text { Minimum } \\
\text { temperature }\left({ }^{\circ} \mathrm{C}\right)\end{array}$ & 4.0 & 18.0 & 15.0 & -1.0 & 9.0 & 0.03 \\
\hline Precipitation $(\mathrm{mm})$ & 29.1 & 83.4 & 96.1 & 10.0 & 218.7 & 20.2 \\
\hline $\begin{array}{l}\text { Maximum } \\
\text { humidity } \\
(\%)\end{array}$ & 88.3 & 91.6 & 93.6 & 85.3 & 89.6 & 1.63 \\
\hline $\begin{array}{l}\text { Minimum } \\
\text { humidity } \\
(\%)\end{array}$ & 36.4 & 49.2 & 57.3 & 38.1 & 45.2 & 1.65 \\
\hline $\begin{array}{l}\text { Maximum wind } \\
\text { Speed } \\
(\mathrm{m} / \mathrm{s})\end{array}$ & 29.1 & 26.4 & 25 & 26.1 & 26.6 & -1.04 \\
\hline $\begin{array}{l}\text { Minimum wind } \\
\text { Speed } \\
(\mathrm{m} / \mathrm{s})\end{array}$ & 5.7 & 5.6 & 2.7 & 4.8 & 4.7 & 1.16 \\
\hline
\end{tabular}
the maximum wind speed is reduced, other climatic factors are increasing trend.

TABLE II. THE VARIATION OF CLIMATE ELEMENTS OF BAOJI IN 2007-2013

From (Fig. 1), it can be seen that the annual average concentration of $\mathrm{SO}_{2}$ is $0.023 \mathrm{Mg} / \mathrm{m}^{3}$, and the maximum concentration is $0.024 \mathrm{Mg} / \mathrm{m}^{3}$, as well minimum value is 0 .
$023 \mathrm{Mg} / \mathrm{m}^{3}$. Annual average concentration of $\mathrm{NO}_{2}$ is 0.026 $\mathrm{Mg} / \mathrm{m} 3$, and the maximum value is $0.027 \mathrm{Mg} / \mathrm{m}^{3}$, while the minimum value is $0.025 \mathrm{Mg} / \mathrm{m}^{3}$. The average concentration 
of PM10 is $0.1024 \mathrm{Mg} / \mathrm{m}^{3}$, the maximum average of 0.110 $\mathrm{Mg} / \mathrm{m}^{3}$, and the minimum value is $0.095 \mathrm{Mg} / \mathrm{m}^{3}$. Air pollution index is the same change as pollutants density, but the comprehensive index of air environment is decreasing. The pollution density of PM10 is the biggest and is main pollutants in Baoji, while the average density of PM10 exceeds the national second-class index, and pollution is serious. Before 2010 the density of PM10 declined slowly trends then increase, it is related to environmental protection aware of governance. The densities of $\mathrm{SO}_{2}$ and $\mathrm{NO}_{2}$ have approximately the same trend change as PM10 and is only slightly change.

It can be seen from (Fig. 2), PM10 pollution index is the higher than $\mathrm{SO}_{2}$ and $\mathrm{NO}_{2}$. The $\mathrm{SO}_{2}$ and $\mathrm{NO}_{2}$ pollution index exhibit fluctuations. PM10 pollution index in 2007-2009 was a downward trend, then upward. $\mathrm{SO}_{2}$ and $\mathrm{NO}_{2}$ pollution index is rising slowly. In 2008, the $\mathrm{NO}_{2}$ pollution index is higher than that of $\mathrm{SO}_{2}$ pollution index. In other years $\mathrm{NO}_{2}$ pollution index is higher than that of $\mathrm{SO}_{2}$ pollution index. Overall $\mathrm{SO}_{2}$ pollution index is greater than $\mathrm{NO}_{2}$ pollution index.

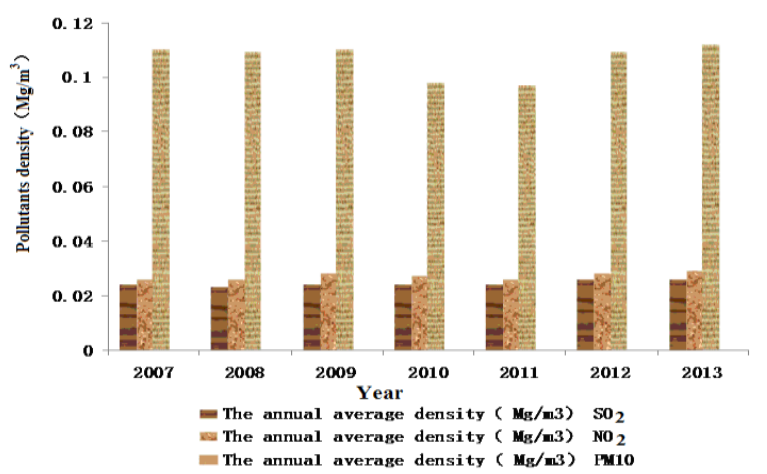

Figure 1. Annual variation trend of air pollutants density in Baoji

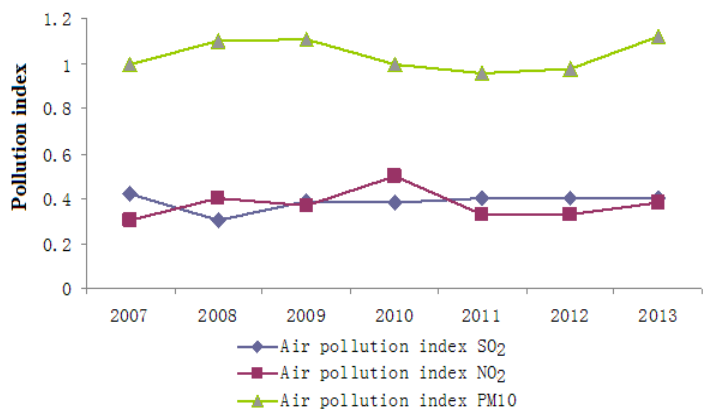

Figure 2. Annual variation trend of pollution index of air environmental quality in Baoji

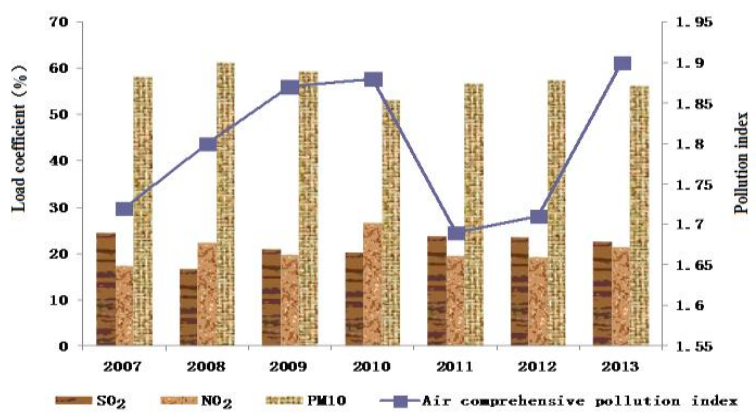

Figure 3. Change of air pollution load coefficient and comprehensive pollution index

From (Fig.3) it can be seen that comprehensive air pollution index exhibit fluctuations. During 2007-2009, it showed a increasing trend, followed by decreased then increased. The minimum comprehensive pollution index is in 2011, and the highest comprehensive pollution index is in 2013. It indicates that atmospheric environmental quality is poor in Baoji. The load coefficients of air pollutants of $\mathrm{SO}_{2}$, $\mathrm{NO}_{2}$ and PM10 are concluded (Fig. 3). It can be seen that PM10 pollution load coefficient was the highest, followed by $\mathrm{SO}_{2}$, then is $\mathrm{NO}_{2}$. This is because that Baoji is still a heavy industry City, and there are more emissions of particulate pollutants. With the rapid increase of motor vehicles, exhaust of $\mathrm{SO}_{2}$ and $\mathrm{NO}_{2}$ is also increasingly serious.

TABLE III. RANK CORRELATION COEFFICIENT AND SIGNIFICANCE LEVEL

\begin{tabular}{ccc}
\hline $\mathbf{Y}$ & $\begin{array}{c}\text { WP significant level } \\
\boldsymbol{\alpha = 0 . 0 5}\end{array}$ & $\begin{array}{c}\text { WP significant level } \\
\boldsymbol{\alpha}=\mathbf{0 . 1 0}\end{array}$ \\
\hline 5 & 0.9000 & 1.0000 \\
6 & 0.8290 & 0.9430 \\
7 & 0.7140 & 0.8930 \\
8 & 0.6430 & 0.8330 \\
9 & 0.6000 & 0.7830 \\
10 & 0.5640 & 0.7460 \\
12 & 0.5060 & 0.7120 \\
14 & 0.4560 & 0.6450 \\
16 & 0.4250 & 0.6010 \\
18 & 0.3990 & 0.5640 \\
20 & 0.3770 & 0.5340 \\
\hline
\end{tabular}

TABLE IV. RANK CORRELATION COEFFICIENT TREND OF DIFFERENT POLLUTANTS

\begin{tabular}{cclc}
\hline Pollutants & Rs & Trend & Significant \\
\hline $\mathrm{SO}_{2}$ & 0.2142 & Rising trend & No \\
$\mathrm{NO}_{2}$ & 0.0142 & Rising trend & No \\
$\mathrm{PM} 10$ & -0.7464 & Downward trend & pass \\
\hline
\end{tabular}

From (Tab.3, Tabl.4), it can be seen that the significance level of 0.05 , when $\mathrm{Y}=7$, or the critical value $\mathrm{WP}=0.7140$, and compared with the value of Rs calculated, the Rs of $\mathrm{NO} 2$ and $\mathrm{SO}_{2}$ are positive rank correlation coefficient ,but rank correlation coefficient of PM10 is negative, which indicates that changes of $\mathrm{SO}_{2}$ and $\mathrm{NO}_{2}$ are slowly rising trend, and PM10 change is on the decline. It indicates we need to find out reasonable control measures to reduce the emissions of 
$\mathrm{SO}_{2}$ and $\mathrm{NO}_{2}$, to improve the atmospheric environment quality.

\section{B. Affecting Factor Analysis}

In Baoji, heating period is long in winter, which leads to higher pollutant concentration, and south, west and north of Baoji surrounded by mountains and influenced by topography, pollutants is not easy to spread. Due to weather systems, temperature is low and precipitation and wind speed are small, while storms can blow Baoji City from North-west, so as to make the serious dust weather, lower visibility and decline of environmental air quality. In addition Baoji is a heavy industry city, energy structure is main the burn coal. Exhaust emission becomes an important source of air pollution in Baoji. Especially, the technology advancements have great role upon the direct sources of air pollution, including cars, machinery, energy infrastructure, combined mobility of transportation modes being applicable. The burn coal and pollutants emissions of motor vehicle and large factories continue to increase PM10, NO2 and $\mathrm{SO} 2$ content and also caused serious the atmospheric environment pollution. Therefore, the reasonable measures should be taken to reduce emissions, use patterns of energy, and take advantage of clean energy, thereby reducing air pollution to improve atmospheric environment quality.

\section{CONCLUSION}

The above analysis shows, atmospheric environmental quality Baoji city is the lower than national atmospheric environmental quality standards, and it is moderately polluted state. In atmospheric pollutants, index of PM10 pollutant is highest, followed by the $\mathrm{SO}_{2}$, and then the $\mathrm{NO}_{2}$. Load rank correlation coefficients of $\mathrm{NO}_{2}$ and $\mathrm{SO}_{2}$ show a slow upward trend respectively, but PM10 pollution load coefficient is a significant downward trend. The climate elements have great influences on diffusion of atmospheric pollutants and coal combustion and vehicle exhaust emissions are the main sources of air pollution.

\section{ACKNOWLEDGMENT}

This work was supported by the National Social Science Foundation Project of China (15XZZ012), Key Laboratory Foundation Project of Shaanxi Province (13JS010), Baoji University of Arts and Science Project (ZK16061) and Geography Key Discipline Project.

\section{REFERENCES}

[1] K.L. Civerolo, G. Sistla, S.T. Rao and D.J. Nowak, The effects of land use in meteorological modeling: implications for assessment of future air quality scenarios atmos, Environ. 34(10):1615-1621 (2000).

[2] D.J. Nowak, K.L.Civerolo, RaoST and D.E.Crane, A modeling study of the impact of urban trees on ozone atmos, Environ. 34(10):16011613 (2000).

[3] M.R. Zhao, F. Ying, L. Jiao, S.M. Hong and Z.F. Liu, Analysis on the variation trend and influence factor of ambient air quality in Xaoshan district. Environmental Pollution \& Control. 34 (8):44-52 (2012).

[4] J. Zou, Y. Liu, The Ambient Air Quality and Trends in Cities of Sichuan Province, Sichuan Environment. 29 (4) : 49-53 (2010).

[5] Q.X. Wang, W. Zhao and G.Y. Zhao, Change and Influencing Factors for Ambient Air Quality of Harbin City, Environmental Science and Management. 39(15):130-134 (2014).

[6] D. Archer, The importance of the natural atmospheric $\mathrm{CO} 2$ concentration to human historical evolution, Climatic Change. 138:111 DOI 10.1007/s10584-016-1725-y (2016).

[7] M.T. Ma, Y.F. Han and L.Y. Song, Variation Trend of Atmospheric Environmental Quality in Shanghai in Recent Years, Sichuan Environment. 29(2):61-69 (2010).

[8] T. Li, G. Mai, Y.H.Liu, W.J. Xu and Q.R. Zhu, Analysis of the urban environmental air quality and its trends in Guangzhou in recent years, Journal of Safety and Environment. 13(1):124-128 (2013).

[9] H. D. Kan, B. H. Chen, Particulate air pollution in urban areas of Shanghai, China: health-based economic assessment, Science of the Total Environment. 322:71-79 (2004).

[10] J. zhang, Y.N. Geng, Change trend of environmental quality based on Spearman method in Baoji, Journal of Mudanjiang University. 16 (4):113-114 (2007).

[11] SEPA, GB3095-1996: Ambient Air Quality Standard factory, China Environmental Science Press (Beijing ,1996) pp.1-5. 